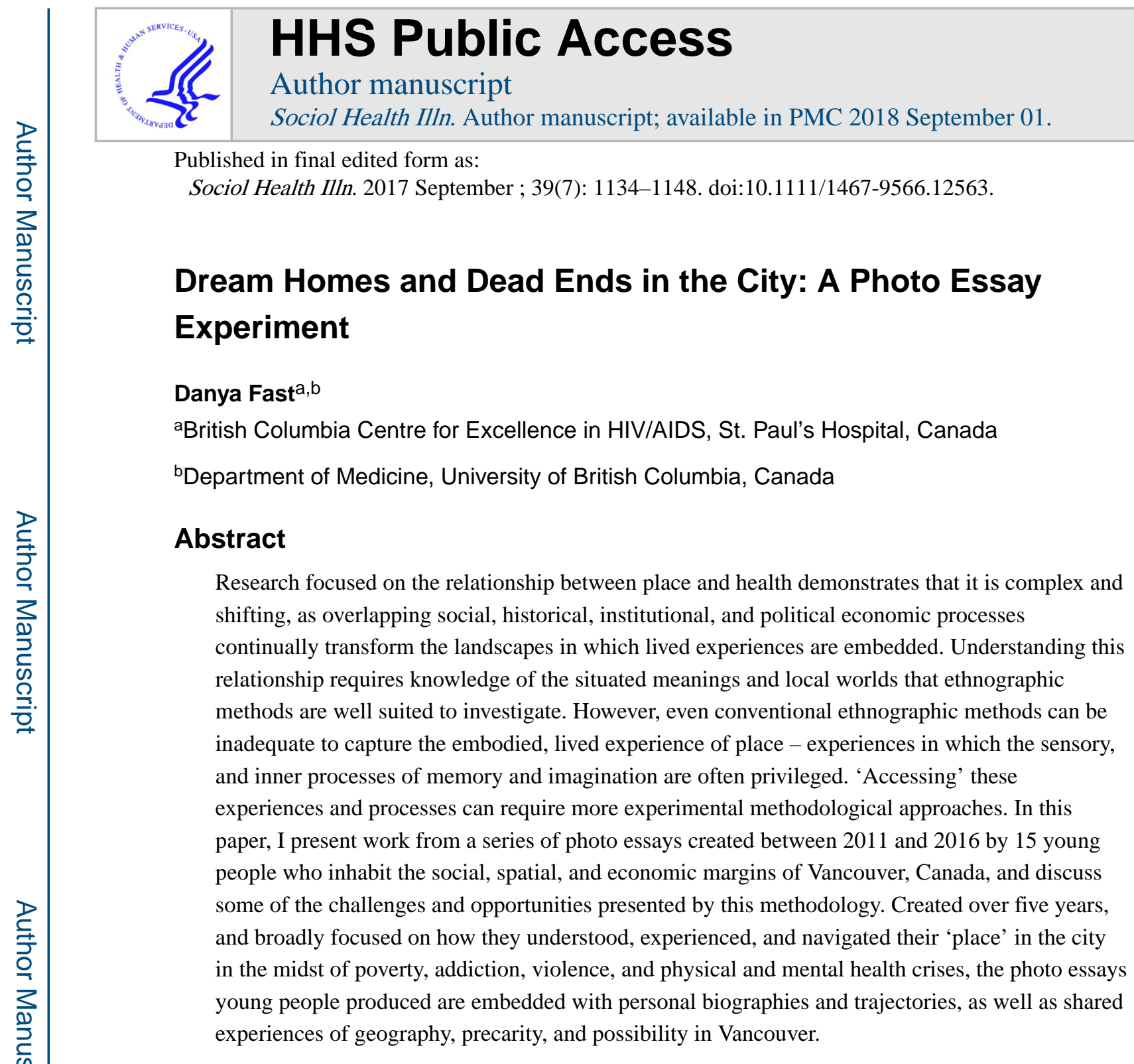

\title{
Keywords
}

youth; urban drug scenes; auto-photography; experimental methods; ethnography

In this paper, I present work from a series of photo essays created between 2011 and 2016 by 15 young people who use drugs in the social, spatial, and economic margins of Vancouver, Canada, and discuss some of the challenges and opportunities presented by this experimental methodological approach. The youth who participated in this photo essay project are part of an urban population for whom everyday living has been rendered problematic in similar ways. In the places of their childhoods, the overwhelming majority grew up in circumstances marked by poverty, violence, and routinized physical and psychological crises. Across time and place, ongoing experiences of violence took the form of physical assaults, but also encompassed the everyday violence of perpetual uncertainty

Address for correspondence: Danya Fast, Research Scientist, British Columbia Centre for Excellence in HIV/AIDS, 608-1081 Burrard Street, Vancouver, B.C. V6Z 1Y6 CANADA, dfast@cfenet.ubc.ca.

This paper is dedicated to Lee. 
and dislocation. Approximately half were taken from their birth families by the state, and subsequently grew up cycling between government foster care homes. Half have spent time in psychiatric facilities, juvenile detention centers, and prisons. Youth's experiences across time and place are also marred by the structural violence of historical and institutional forces ranging from the ongoing effects of colonialism in Canada (over one third of project participants are of Indigenous ancestry), to vastly inadequate monthly social assistance payments in the Province of British Columbia. On the streets of Vancouver, their social suffering takes the form of addictions to crack cocaine, heroin, and crystal methamphetamine, highly volatile drug deals and romantic relationships, and street based homelessness. It is reflected in ascribed and adopted labels like 'junkie' and 'crackhead,' 'drunken Indian' and 'white trash,' as well as other, seemingly more innocuous policy relevant codes like 'street youth' and 'NFA [no fixed address].' Created over five years, and broadly focused on how youth understood, experienced, and navigated their 'place' in the city in the midst of poverty, addiction, violence, and physical and mental health crises, the photo essays participants produced are embedded with personal biographies and trajectories, as well as shared experiences of geography, precarity, and possibility in Vancouver.

\section{Background and Setting}

This photo essay project was nested within a larger research program conducted from 2008 to 2016, which was broadly focused on how embodied 'senses of place' shape the addiction trajectories and health outcomes of young people in the context of entrenchment in Greater Vancouver's street based drug scenes (Feld and Basso 1996). This larger research program began when I was hired as an ethnographer by the British Columbia Centre for Excellence in HIV/AIDS to conduct longitudinal interviews and exploratory ethnographic fieldwork with approximately 70 young people enrolled in the At-Risk Youth Study (ARYS) cohort, comprised of more than 1200 'street involved youth' in Greater Vancouver (Wood 2006). ARYS cohort participants are between 14 and 26 years of age and self report use of illicit drugs (other than or in addition to marijuana) at the time of enrolment. During the eight year period of this larger research program, therefore, most of my study participants moved, developmentally and otherwise, from adolescence into young adulthood. I retain the use of the terms young people and youth in this paper in order to differentiate my participants from a largely distinct adult street entrenched population in the Vancouver setting, and to avoid confusion.

The city of Vancouver is celebrated as one of the world's most beautiful, cosmopolitan, and livable cities. More than once, young people referred to Vancouver as 'The Best Place on Earth' - a slogan that appeared on license plates and other government advertising for the Province of British Columbia leading up to the 2010 Winter Olympic Games.

Simultaneously, Vancouver is criticized as the site of a thriving inner city drug scene, which is generally understood to include the Downtown Eastside neighborhood as well as an adjacent area I am calling the Downtown South, where the majority of 'street youth' drop-in services and shelters are located. Processes of gentrification and poverty management are rapidly transforming both of these neighborhoods; increasingly, the aesthetic of new condo developments and expensive eateries intermingle with well worn storefronts and single room 
occupancy hotels (SROs), as well as an expanding number of supportive housing buildings, not-for-profit agencies, and frontline research offices.

Youth who are visibly homeless and addicted to drugs on the streets of Vancouver are often defined through their relationships with the Downtown Eastside and Downtown South including in my own earliest work (e.g., Fast, et al. 2009a; Fast, et al. 2009b). Both of these neighborhoods have become zones of intense surveillance and monitoring, where people who use drugs are subject to the gaze of researchers, public health experts, service providers, police, activists, artists, and the media. However, by the time I had begun my PhD in 2009, my research had shifted to a more immersed, ethnographic exploration of how a smaller group of 25 youth understood, experienced, imagined, and navigated their 'place' in the city of Vancouver much more broadly. ${ }^{1}$ Particularly from 2011 to 2013, this involved spending hundreds of hours in the places where young people were living, working, socializing, and accessing various services and bureaucracies. These geographies extended far beyond Vancouver's inner city, and we spent a significant amount of our time together on public transit or in my car, travelling between various nodes of social and economic activity. These include the bustling transportation hub at Broadway and Commercial Street in East Vancouver (where youth congregate to meet up, 'hook up', drink coffee, and deal drugs); the flop houses, homeless camps, and informal recovery houses scattered throughout the suburbs of Surrey, Port Coquitlam, New Westminster, and Burnaby; and shoplifting hot spots like Metrotown Mall and Lougheed Town Centre. Youth's movements through the city are also shaped by elaborate geographies of Twelve Step meetings and endless appointments with social workers, housing workers, welfare workers, probation officers, methadone doctors, and officials from the BC Ministry of Children and Family Development (where a small number of youth, including two of the photo essay project participants, have been involved in legal proceedings related to determining custody of their child or children).

In addition to spending time with young people in the places where they lived out their everyday lives, beginning in 2011 I also engaged an even smaller group of 15 participants (drawn from the 25 youth described above) in more experimental methodological activities. I used audio recorded walking tours led by these youth to explore how, in particular moments, they understood, experienced, and performed their sense of place in the city (Guano 2003; Moretti 2008). Some youth narrated these tours, while others preferred to remain largely silent. I always brought my digital SLR camera along, inviting youth to take photos or to direct me to take certain photos (I did not take photos uninvited during these outings). Almost without exception, youth embraced this invitation as an opportunity for creative expression - or, less often, to 'objectively' document the material conditions of their lives - and to learn the basics of how to use, as they put it, a 'nice,' 'real,' 'fancy,' and 'expensive' camera.

\footnotetext{
${ }^{1}$ I first interviewed eleven of these youth in 2008, and six of them in 2009. The eight new participants were either close friends of, or romantically involved with, these 17 youth. This group was comprised of 16 young men and 9 young women (including one transgender young woman), all of whom identified as straight. Approximately three quarters of these youth are Caucasian, while the remaining one quarter are Indigenous. One young man is African Canadian. Half of these young people are parents, although none had custody of their children during the research period.
} 
The walking tours allowed me to gain a richer, embodied sense of the places young people inhabited. They were effective in surfacing some of the layers of experience sedimented into the urban landscape across time, bearing in mind that the goal of performative methods like walking tours is not to uncover an objective past or memory, but rather to produce what we call memory through the act of performance (Irving 2007; Irving 2010). Also beginning in 2011, I engaged this same group of 15 youth in the creation of photo essays related to their sense of place in the city, for which they were invited to use both my SLR camera whenever we were together, and disposable, flash enabled film cameras that they could also take away and use independently. Beyond the photos they had taken as part of the walking tours - some of which were eventually incorporated into their photo essays - this photo essay project seemed to allow youth to re-engage with the city in relation to particular memories, life events, and imagined futures in even more compelling ways. There seemed to be something about creating a visual record of their sense of place in the city that raised the stakes of participation in this project for youth - for better and for worse, as I will discuss below. The photo essay project became an emotionally charged experiment that ultimately stretched across years of participants' lives.

\section{The Photo Essay Project}

Research focused on the intersections between place and the lived experience of addiction, blood borne infections, mental health crises, and violence demonstrates that these intersections are complex and shifting over time, as overlapping interpersonal, historical, institutional, and political economic processes continually transform the landscapes in which everyday, lived experiences are embedded (Garcia 2010; Meyers 2013; Raikhel and Garriott 2013). Understanding these intersections requires knowledge of the situated meanings and local worlds that ethnographic methods are well suited to investigate. However, even conventional ethnographic methods (e.g., prolonged fieldwork, conversations with participants spanning several years) can be inadequate to capture the embodied, lived experience of place - experiences in which the sensory, and inner processes of memory and imagination are often privileged (Irving 2007; Irving 2010). 'Accessing' these experiences and processes, which are so central to the practices of everyday life, and yet so challenging to articulate, can require more experimental or 'live' methods (Back 2007; Pink 2006).

The value of incorporating arts-based methods into health research is increasingly being recognized, including research focused on drug use and the social, structural, and environmental production of 'risk' (Bourgois and Schonberg 2009; Fraser and al Sayah 2011; Rhodes and Fitzgerald 2006). In addition to facilitating more nuanced understandings of the complex and shifting relationships between place and health, these methods can also be an effective means of engaging 'at risk youth' in research processes. The creation of photo essays by research participants is one example of an arts-based method that can be effective in surfacing the layers of experience that are incorporated into places and bodies across time (Fast 2014; Irving 2007; Irving 2010). Moreover, this method can facilitate a more collaborative approach to research and representation than conventional research methods (Byrne, et al. 2016; Johnsen, et al. 2008). On the streets of Vancouver, where a large number of official records about 'street youth' compete for authority, this photo essay project allowed young people to reflect on, critique, and construct their own expert records 
of their everyday lives in the city. Instead of limiting understandings of these lives to statistics, or characterizations of the biological body or social structures (Irving 2007), this photo essay project opened up new ways of thinking about how young people in the margins inhabit the city in complex and oftentimes expansive ways, whether through memory, imagination, or a deep desire for things to be otherwise (Biehl and Locke 2010).

Youth and I worked together for time periods ranging from 2 to 5 years on the creation of their photo essays - developing a theme across numerous conversations in my office and the field, shooting and re-shooting images during multiple morning, afternoon, and evening sessions that we dedicated specifically for this activity, and discussing images. A photo essay can be defined as a series of images that are intended to tell a story or evoke a series of emotions in the viewer. They range from purely photographic works, to photographs with captions, to written essays with a few or many accompanying photographs. When this project began in 2011, I presented young people with all of these options and told them that their photo essays needed to be broadly focused on their 'place' in the city - however they wanted to interpret that prompt. I imagined that youth would appreciate my reluctance to provide more detailed instructions and over determine the content of their images and photo essays. However, participants quickly and forcefully made it clear that they needed much more instruction and information. Most young people were initially very apprehensive about their ability to 'do the project correctly,' in spite of my insistence that it was not about correctness but rather their unique ways of seeing the world. All participants brought with them a history of repeated 'failures' in the public school system (only two youth had completed high school). While their 'failure' to complete school projects and homework was almost certainly a result of the violence and uncertainty they were experiencing at home (if they had a home) at that time, youth nevertheless recalled an inability to 'understand and do what is being asked of me' as a personal shortcoming. After a series of failed attempts to better explain the project, I eventually showed them different kinds of photo essays produced by a number of prominent photographers, including Stephen Shore, Wolfgang Tillmans, and Sophie Calle. It was when I began showing them images like those from Stephen Shore's American Surfaces and Uncommon Places (for which Shore took many images of everyday objects and rooms) that youth began to make general comments like, 'Oh - I think I can do that!' and engage in more specific reflections like, 'Okay, so, I could take a picture of my food tray at the shelter and that would be about what it's like to always be in institutions...'

Examples of photo essays that focused on everyday objects and spaces, but not people, were also imperative because the content of youth's images was constrained by legal and university ethical guidelines. Canada's laws prohibit the reproduction of a stranger's image without his or her consent, so I instructed youth to ensure that there were no recognizable individuals in any of the shots they might eventually want to share online or in presentations and publications. Youth themselves could also not appear in any images that would eventually be shared, because of strict institutional guidelines regarding the identification of young people in the context of illicit drug use and crime. It is interesting to note that each participant chose to take a self portrait as part of their photo essay, but these images could not be included here. For this project, young people had to take photographs that were 'empty' of people, and yet symbolic of social phenomena. Initially, this felt like a limitation. However, as the project took shape, the 'emptiness' of the images became a part of what 
made them compelling. Youth's absence from the visual content of their images is a powerful metaphor for the ways in which 'hypermarginalized' (Lopez 2014) individuals are shut out of particular urban landscapes in Vancouver. However, this absence also prevented participants from being locked into one moment, subject position, or place.

During our morning, afternoon, and evening sessions together, it was clear that the process of moving through and re-engaging with the city in order to shoot particular images - on foot, via public transit, and occasionally in my car - was not unlike the walking tours, in that it was a highly performative means of creating space for something new to emerge in relation to particular life events, memories, and imaginings (Irving 2007; Irving 2010). However, the itineraries young people envisioned for their photo essays were much more ambitious in comparison to the walking tours. Youth were also much more adamant about photographing or not photographing particular places than they were about going or not going to particular places as part of their walking tours. They took me out to the suburbs, to photograph childhood homes (many of which they were no longer welcome in) and neighbourhoods. As their circumstances changed, they proudly photographed new apartments and worksites. Some youth wanted to photograph places they had never been before, such as Vancouver's North Shore Mountains (a popular destination for tourists as well as those looking to 'get away' from the city and engage in various leisure activities). Their itineraries and 'picturing practices'(Crang 1997) often reflected a desire to reimagine the possibilities of place in the city.

When youth used my SLR camera to shoot images, they tended to take dozens of photographs in rapid succession. Some of these images were related to the themes of their photo essays, but many were not, and it was interesting that very few youth ultimately chose images taken on my camera to be included in their final photo essays. Rather, participants tended to select images that they had carefully composed, sometimes while with me, but more often on their own time, with the disposable cameras that I regularly provided them with. Youth generally attributed this to chance. However, I would argue that both the simpler technology of the disposable cameras, and the ability to take images without me present, worked better for participants in the context of this project, in which many youth remained self conscious about their ability to 'take photographs correctly,' and often chose to capture emotionally charged objects and spaces during moments of private, and sometimes painful, reflection. Previous work has emphasized the challenges of providing disposable cameras to individuals who are living in circumstances of entrenched poverty and crime, including the possibility that participants could become a target for robbery (Byrne, et al. 2016; Johnsen, et al. 2008). In the context of the everyday emergencies of life on the streets, participants can easily lose their cameras or may need to sell them. All of these were serious concerns in my setting as well, so it was surprising when young people consistently brought their cameras back for development, often full of carefully framed images taken across a wide range of locations. One reason for this consistency could be the fact that youth were paid a $30 \mathrm{CAD}$ cash honoraria for each camera they returned (which they had to keep for a minimum of one week to discourage the idea of quickly using up the camera in order to get the honoraria). These honoraria undoubtedly exceeded the resale value of the cameras on the streets. However, it would be inaccurate to conclude that youth's diligence came down to considerations of money - after all, participants could have taken 24 identical images of a 
city sidewalk, and still received the honoraria. Rather, I would argue that their careful work with these cameras was a reflection of the stakes of participation in this project for youth, through which they were recording or 'staging' (Back 2007) highly meaningful senses of place and self in the city at a particular, youthful moment in time.

While this was not a Photovoice project, the images and photo essays youth produced, as well as the extended process of their creation, facilitated some of my most lively and productive conversations with them about their senses of place in the city, and how they were navigating the rapidly evolving politics of place in Vancouver. Towards the end of the project, all 15 participants agreed to share their images with each other, and became enthralled by the ways in which other youth's work spoke to or contradicted their own experiences. This provided a rich opportunity for further conversations. I was able to audiorecord many of these conversations in the field; I also conducted two more formal, semistructured audio-recorded interviews with participants about the photo essay project annually. Beginning in 2013, transcripts of these interviews and field recordings, as well as field notes related to the project, were coded using ATLAS.ti software, using a coding framework that captured broad, overlapping themes (e.g., 'home making,' '(re-)institutionalization,' 'urban transformation'). Youth produced more than a thousand images in total. Also beginning in 2013, these images were manually sorted into folders using the same coding framework that was applied to transcripts and field notes. The coding framework emerged both from the image content (e.g., hundreds of images of institutional and domestic spaces) and ongoing conversations and interviews with youth. From 2013 to 2016, the coding framework was continually refined to reflect the emergence of additional overlapping themes (e.g., 'disappearance').

From finding ways to explain the project to youth, to recognizing the value of the disposable cameras, to analyzing the sheer volume of visual, audio, and textual data generated - at every stage, the photo essay project had an improvisational feel (Cerwonka and Malkki 2007). This could be viewed as a shortcoming, and it has been noted that the methodology of auto-photography (i.e., photographs taken by research participants) is currently underdeveloped and perhaps especially under described in the existing literature (Byrne, et al. 2016). However, this improvisational process produced knowledge integral to my larger research program, and shifted the course of this research program in significant ways. In particular, it was the photo essays, and the circumstances of their production, that powerfully underscored for me young people's deep desires for alternative forms of belonging and becoming in the city in spite of their current location in the margins, and I began to notice the moments in which youth were willing to entertain extraordinary levels of danger, and fantasy, in order to find a way into the life worlds they imagined for themselves in Vancouver. These are ideas that I have since taken up in a number of different textual analyses (Fast 2016; Fast, et al. 2014; Fast, et al. forthcoming).

Photographs have not been edited or retouched subsequent to developing/uploading. As has been observed in the context of similar projects (Johnsen, et al. 2008), youth expressed a desire for their real names to appear under the images they took, instead of the pseudonyms used throughout this paper for the purpose of confidentiality. Ethical approval for this study 
was obtained from the University of British Columbia and Providence Health Care Behavioral Research Ethics Boards.

\section{Dream Homes and Dead Ends}

The themes young people chose to pursue were diverse. Terry's photo essay centered on the places of his childhood, which he imagined 'finding his way back to' (Images 1, 2). While his family did not allow him to step foot on the property of his childhood home, he imagined that their unconditional support would motivate him to quit injecting drugs and doing crime for good. Through his photo essay, Terry seemed to be actively re-imagining an idealized past in relation to a pained present, in which homelessness, an accelerating addiction to heroin and crack cocaine, and repeated incarcerations and hospitalizations were increasingly coming to seem like 'inevitable' aspects of lived experience in the city. One of his images in particular generated significant discussion when it was shared among the group in 2013. While photographing the suburb in which he grew up in 2011, Terry (then age 21) captured his shadow across the tall, yellowed grass that edged an open field (Image 2). Some young people felt that the small size of Terry's shadow, cast onto the scenic backdrop of a field in the bright sun, symbolized a sense of 'disappearing' from the urban landscape (a theme I will discuss further below). Others, including Terry, thought that it symbolized a desire to be a part of the scene, and hope for a different kind of future in the city.

Carly and Connor focused on the home making project they were navigating in an attempt to get their children returned to them by the Ministry of Children and Family Development (MCFD; Images 3,4). Many of their photographs meticulously document aspects of the one bedroom apartment the two of them were finally able to secure in 2013. Images of a neatly made up bed, cupboards full of pots and pans, and a fridge full of food in many ways mirrored the process of inspection carried out by the social worker on her impromptu visits to the apartment, during which she evaluated whether it would be a suitable home for two small children. In addition, Carly and Connor's images reflected an elaborate geography of government and non-government agencies, food banks and Twelve Step meetings - which they were required to attend daily in 2013 if they wanted to be successful in 'getting their kids back.' Ultimately, the two of them were denied custody of their daughters in early 2014. A few months before they received the court's decision, Carly and Connor both relapsed on crack cocaine, an event which they connected to the 'stress' of having to continually prove they were worthy parents. While they were able to hide their relapses from the social worker and other professionals for a time, it was Connor's worsening schizophrenia that ultimately raised the alarm during the requisite 'family meetings' at the MCFD office. 'I guess we just couldn't hold it together,' Carly berated herself, as she reflected on her photo essay in 2014. 'We broke down. And then you just decide to keep going [with the drugs], because really, where else are you going in life?'

The photo essays young people produced illustrated what was at stake in their lives during a particular moment in time. However, they could also reflect desires to create new stakes in the city. I met Lee in 2008 when he was 20 years old and living at a shelter in downtown Vancouver. When I asked if I could follow up with him after our first meeting, he immediately distanced himself from my research. 
'Actually, I was thinking about finishing my [high]school this year,' he told me optimistically, as we sat together in my office in downtown Vancouver. 'Just to go to college or something. I wanna pursue certain dreams in this city, right? I'm gonna get a place and I'm gonna get a job here really soon, so I probably won't be around these service places here that much.' Despite this, Lee became one of the central participants in my research, including the photo essay project.

Like Lee, most of the young people I knew came or fled to downtown Vancouver from elsewhere - other cities, hometowns, and First Nations reserves. In relation to these places, Vancouver was often framed as the site of new and exciting opportunities for work and leisure. Once in Vancouver, youth found themselves inhabiting the social, spatial and economic margins of the city; however, the city of Vancouver itself was not marginal. As Lee and I were looking over his images in early 2012, I was struck by the numerous photographs he had taken of Vancouver's most desirable downtown living spaces and parks, and of various construction sites (Images 5,6). His images of construction sites led me to assume that he was developing a political commentary - on gentrification, for example. But instead Lee pointed out small details in the photographs and explained that he planned to get a job in construction doing a particular kind of welding once he had 'pulled his life together.' In 2012, Lee was living in substandard SRO housing in the heart of Vancouver's inner city drug scene. It was so substandard that he frequently opted to sleep outside or in shelters instead, rather than deal with bed bug infestations, constant noise and violent incidents in his building nearly every night. And yet, Lee did not want his photo essay project to focus on his marginality - in fact, he adamantly refused to take photographs of where he lived and slept. Instead, he focused on the comfortable future and 'progress' he imagined for himself in the city: going to work, playing sports on the weekends and in the evenings, and living in what he referred to as his 'dream place.' To an extent, Lee used his photo essay to assert his inclusion in this urban imaginary.

Lee and a number of other young people struggled to reconcile their social, spatial, and economic exclusion in the city with a desire to understand themselves as a part of it in particular ways. Particularly as time passed, and youth became increasingly entrenched in material deprivation, homelessness, addictions, and crime, a number of participants used the photo essay project to confront the precarity of their existence in the city, and explore a sense that they were somehow 'getting lost' in Vancouver. Conversations about images on this theme underscored that a sense of getting lost was connected to various kinds of 'disappearances' on the streets. There were several ways youth could disappear for periods of time, including various forms of institutionalization. They were incarcerated for drug dealing and theft, and hospitalized for infections, overdoses, and 'mental breakdowns' (Image 7). They went on drug binges, and had to lay low and hide from people as a result of drug debts. Or, they could go 'missing,' as had been the case with the large number of women who vanished from the streets of Vancouver's Downtown Eastside in the late 1990s and early 2000s. Stories were also constantly circulating about individuals who had been pushed out of SRO windows to their deaths, and gangs who disposed of bodies with both hands cut off, so that the police could not identify them. 
A sense of 'getting lost' could also refer to the feeling that young people were somehow moving further away from the kinds of progress they envisioned for themselves in Vancouver. The duration of this photo essay project meant that participants had the opportunity to continually reflect on the images they had produced at various points in the project. This process could be painful.

'I want to progress,' Lee emphasized to me in 2013. He tried to sound confident, but grew increasingly agitated as we looked over his collection of images, and he reflected on the fact that he was nowhere near where he thought he would be when we did our first interview together in 2008. Even though he had recently been moved into cleaner and safer government subsidized supportive housing in downtown Vancouver, he continued to emphasize that these kinds of places were 'dead ends.'

'I'm like - I'm stuck here,' Lee said with frustration. 'Of course, I love the scenery, I love the city, but I hate what's in it - for myself, right? It's been six years since I moved here just trying to live. Trying to not kill myself, you know what I mean? Trying to keep myself from - not going to jail or anything. I wish I had a job or I went to school. I try to-I try to stay busy, right? But sometimes it's really hard - you feel so worthless. So you do drugs you shouldn't do, and you drink even though you shouldn't be doing that, either, right, and you go around with the people you shouldn't be [doing crime] - you know what I mean?'

After a while he added hopefully, 'But, somebody told me that it's easy to die but it's harder - it's harder to live. I think it's a saying - people say that. And it's true. So, I'm going to keep trying - keep going. I have to.'

One of the discussions that emerged through this project was the extent to which, across time, a sense of 'getting lost' in the city could come to be internalized as 'just the way things were' for certain 'kinds' of young people, who consistently found themselves 'getting stuck' in places like hometowns, reservations, jails, hospitals, SROs, supportive housing buildings, and the streets of Vancouver. A growing sense of belonging in the margins - in spite of young people's efforts to position themselves as a part of other urban imaginaries - shaped ways of being at the most intimate level. More specifically, this sense of place shaped what futures were possible to imagine ('I'm stuck here'), and how the present moment was perceived and acted upon ('So you do drugs you shouldn't do, and you drink even though you shouldn't be doing that either, and you go around with the people you shouldn't be [doing crime]'). Vancouver's fractured urban landscape was incorporated into young people's bodies, fueling 'risky' drug use practices and involvement in criminal activities (Bourgois and Schonberg 2007).

I lost touch with Lee in mid 2014. By 2015, rumors started circulating that he had been killed in a violent altercation at a halfway house. The other project participants and I were stunned and heartbroken when I was able to confirm this news, and also shaken by the fact that no one seemed to be able to determine what exactly had happened to Lee, including when he had moved out of his social housing building and into the halfway house. In a devastating progression of events, Lee's death powerfully underscored the themes of 
disappearance and 'getting lost' that a number of young people had explored through their photo essays.

\section{Conclusion}

Reflecting on a longitudinal photography (portraiture) project in a rapidly transforming urban neighborhood, Les Back (2007: 113) writes that 'Photography is a mute form; there is no sound, no smell or touch. But I think there is also an invitation being issued in these photographs.' Similarly, the images young people created in the context of this photo essay project evoke embodied, sensory, and affective experiences in particular places - those they inhabited, but also those they longed to inhabit or return to. Their images have the ability to express without formulating (Stevenson 2014); they convey particular emotions, thoughts, experiences, and dilemmas without fixing particular meanings to the urban landscape through explanation.

While it created numerous opportunities - for the researcher, and for participants - this photo essay project also raises serious ethical questions. The 'emptiness' of young people's photographs, and my inability to attribute them to the photographers except through their pseudonyms, raises questions about institutional ethical guidelines that deny youth their own names and self portraits, even as they protect their confidentiality and ability to disassociate themselves from 'homeless,' 'drug user,' and 'criminal' pasts. This project, which stretched across years of participants' lives, was emotionally charged. For all youth, it involved painful reflections on images that evoked for them particular imbrications of the past, present, and future. This emotional discomfort did not result in any participants leaving the project - in fact, many youth commented on the therapeutic value of the project, in spite of the difficult emotions it raised. However, Lee and other youth's negative reactions to viewing their images across time highlight a normative tension inherent in long term, artsbased projects with those who inhabit the social, spatial, and economic margins, as well as ethnographic research with these populations more generally. Namely, both my larger research program, which began in 2008, and this photo essay project, which began in 2011, inevitably became concerned with capturing change or progress through time - or lack thereof. On the one hand, the photo essay project allowed young people to disrupt dominant discourses and conventions of representation with regard to those in the margins discourses and representations that would, for example, position them as out-of-place in a 'nice' urban space like a community garden, in-place in a 'junkie' space like an SRO, or as simply placeless (Johnsen, et al. 2008). They were able to singularize out of populations and categories like 'at risk,' 'injection drug user' and 'HIV positive,' however briefly. On the other hand, reflecting on images across a number of years underscored the extent to which youth had not been able to achieve deeply desired futures in the city, and continued to be both 'fixed in time' (Murray 2015) and 'fixed in place' (Roe 2009/10). I do not have answers to these ethical questions, except to echo previous arguments that the challenges of more experimental methods do not mean we should retreat back into the ivory tower (Back 2007), or fall back on canonical methodological approaches (Johnsen, et al. 2008). I would stress, however, that this methodology - particularly when used with highly marginalized populations - is perhaps best embedded in long term, highly immersed ethnographic research, in which the researcher has developed close relationships with participants and has 
both the time and resources (e.g., connections to various healthcare providers) to support individuals when they are in distress.

In conclusion, what emerged from this photo essay project is a sense of living in Vancouver as a young person in the midst of 'risks' like poverty, addiction, violence, and physical and mental health crises (Irving 2007). Most importantly, the project created space for a 'plurality of experienced facts' (Irving 2007; Jackson 1996); it allowed youth to perform both a desire for 'dream homes' in one of the world's most livable and beautiful cities, and a sense of 'getting lost' or disappearing from the urban landscape. The embodiment of these contradictory senses of place is perhaps familiar to many young people who inhabit the contemporary global city in the context of hypermarginalization; there, the flashy promise of inclusion continually hits up against the enduring, entrenched 'reality' of exclusion - until sometimes, as Carly put it, something 'breaks.'

\section{Acknowledgments}

The author thanks Terry, Carly, Connor, Lee, Patty, and Joe, and all of the other young people who are not named in this paper, as well as current and past researchers and staff at the At-Risk Youth Study. The project was supported by operating grants from the Canadian Institutes of Health Research (MOP- 81171) and US National Institutes of Health (R01DA033147), and Postdoctoral Fellowships from the Canadian Institutes of Health Research and Michael Smith Foundation for Health Research

\section{References}

Back, Les. The art of listening. Oxford: Berg; 2007.

Biehl, Joao, Peter, Locke. Deleuze and the Anthropology of Becoming. Current Anthropology. 2010; 51(3):317-351.

Bourgois, Philippe, Jeff, Schonberg. Intimate apartheid: Ethnic dimensions of habitus among homeless heroin injectors. Ethnography. 2007; 8(1):7-31. [PubMed: 19777125]

Bourgois, Philippe, Schonberg, Jeff. Righteous dopefiend. Berkeley: University of California Press; 2009.

Byrne, Ellie, Daykin, Norma, Coad, Jane. Participatory Photography in Qualitative Research: A Methodological Review. 2016; 4(2) 2016.

Cerwonka, Allaine, Lisa, H Malkki. Improvising Theory: Process and Temporality in Ethnographic Fieldwork. Chicago: University of Chicago Press; 2007.

Crang, Mike. Picturing practices: research through the tourist gaze. Progress in human geography. 1997; 21(3):359-373.

Fast, Danya. Mapping Senses of Place in an Urban Drug Scene. Medicine Anthropology Theory. 2014; 1(1):180-188.

Fast, Danya. 'My Friends Look Just Like You': Research Encounters and Imaginaries in Vancouver's Urban Drug Scene. Medicine Anthropology Theory. 2016; 3(2):223-243.

Fast, Danya, et al. The multiple truths about crystal meth among young people entrenched in an urban drug scene: A longitudinal ethnographic investigation. Social Science \& Medicine. 2014; 110(0): 41-48. [PubMed: 24721446]

Fast, Danya, Shoveller, Jean, Kerr, Thomas. The material, moral, and affective worlds of drug dealing and crime among young men entrenched in an inner city drug scene. International J Drug Policy. forthcoming.

Fast, Danya, et al. Safety and danger in downtown Vancouver: Understandings of place among young people entrenched in an urban drug scene. Health \& Place. 2009a; 16(1):51-60. [PubMed: 19733496]

Fast, Danya, et al. Coming 'down here': Young people's reflections on becoming entrenched in a local drug scene. Social Science \& Medicine. 2009b; 69(8):1204-1210. [PubMed: 19700232] 
Feld, Steven, Keith, Basso, editors. Senses of place. Santa Fe: School of American Research Press; 1996.

Fraser, Kimberly Diane, Fatima al, Sayah. Arts-based methods in health research: A systematic review of the literature. Arts \& Health. 2011; 3(2):110-145.

Garcia, Angela. The Pastoral Clinic: Addiction and Dispossesion Along the Rio Grande. Berkeley: University of California Press; 2010.

Guano, Emanuela. A Stroll Through la Boca. Space and Culture. 2003; 6(4):356-376.

Irving, Andrew. Ethnography, art, and death. Journal of the Royal Anthropological Institute. 2007; 13(1):185-208.

Irving, Andrew. Dangerous substances and visible evidence: tears, blood, alcohol, pills. Visual Studies. 2010; 25(1):24-35.

Jackson, Michael. Introduction: phenomenology, radical empiricism and anthropological critique. In: Jackson, M., editor. Qualities as they are: new directions in phenomenological anthropology. Bloomington: University of Indiana Press; 1996. p. 1-50.

Johnsen, Sarah, Jon, May, Paul, Cloke. Imag(in)ing 'homeless places': using auto-photography to (re)examine the geographies of homelessness. Area. 2008; 40(2):194-207.

Lopez, Andrea M. The Paradoxes of Poverty: Hypermarginality and Ideologies of Intervention in the 'Compassionate' City of San Francisco, Anthropology, University of New Mexico. 2014

Meyers, Todd. The Clinic and Elsewhere: Addiction, Adolescents, and the Afterlife of Therapy. Seattle: University of Washington, Press; 2013.

Moretti, Cristina. Places and stages: narrating and performing the city in Milan, Italy. Liminalities: a journal of performance studies. 2008; 4(1) (online).

Murray, Karen Bridget. Bio-gentrification: vulnerability bio-value chains in gentrifying neighbourhoods. Urban Geography. 2015; 36(2):277-299.

Pink, Sarah. The future of visual anthropology: engaging the senses. New York: Routledge; 2006.

Raikhel, Eugene, William, Garriott, editors. Addiction Trajectories. Durham and London: Duke University Press; 2013.

Rhodes, Tim, Fitzgerald, John. Visual data in addictions research: Seeing comes before words? Addiction Research \& Theory. 2006:349-363.

Roe, Gordon. Fixed in place: Vancouver's Downtown Eastside and the community of clients. BC Studies. 2009/10; 164:75-101.

Stevenson, Lisa. Life Beside Itself. Oakland: University of California Press; 2014. 


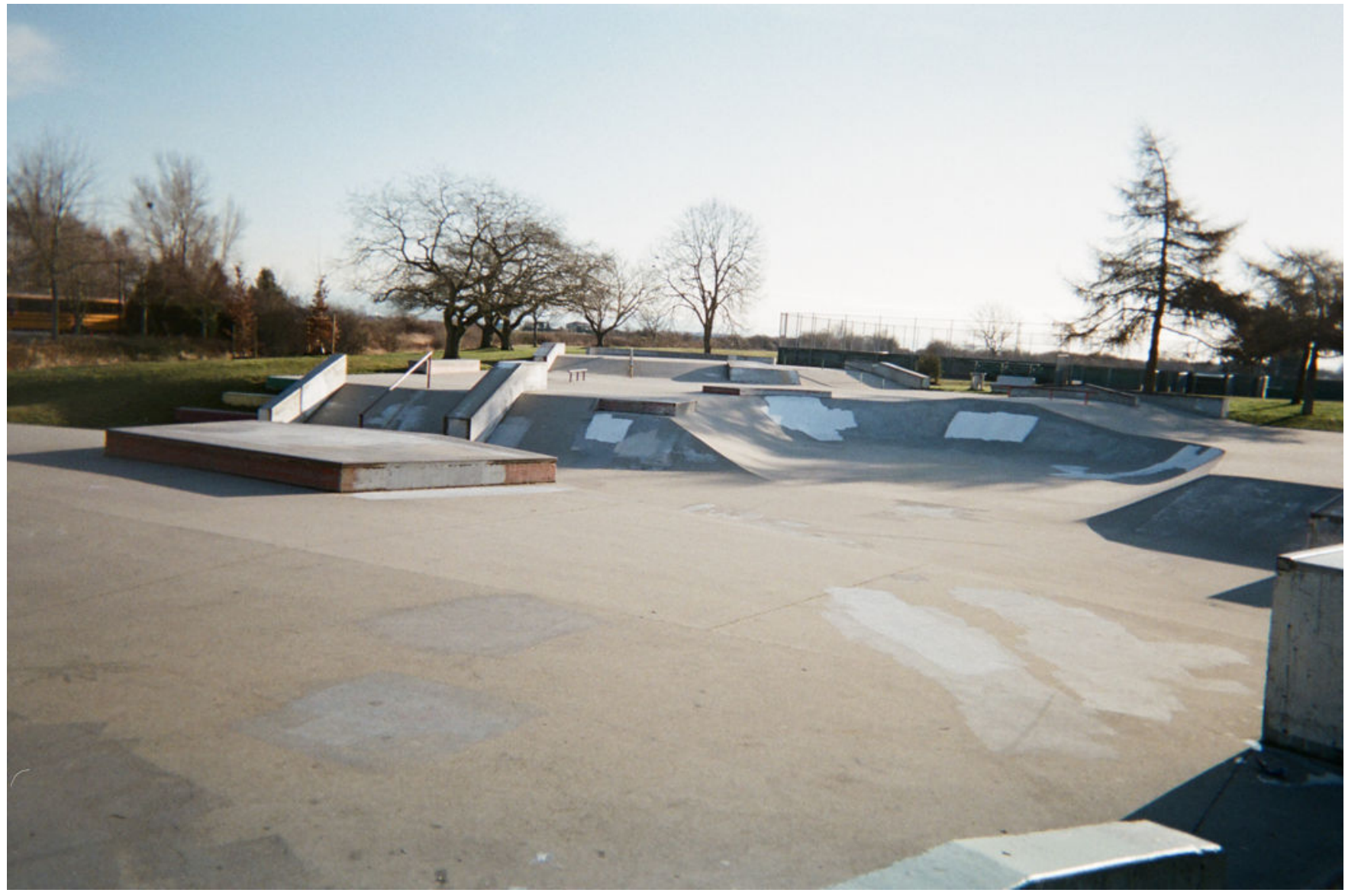

\section{Image 1.}

From The Way Home (Terry, 2011) 


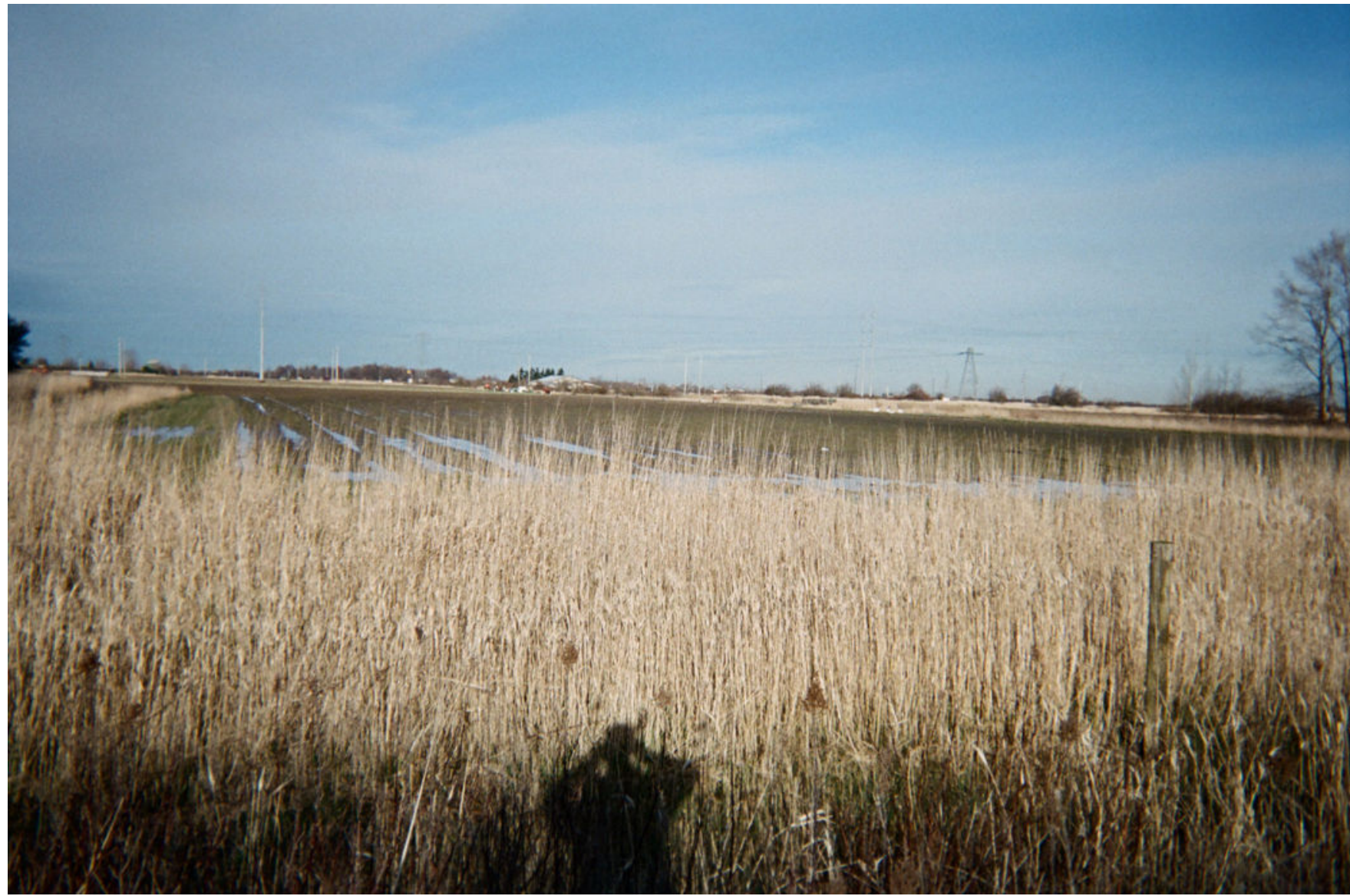

Image 2.

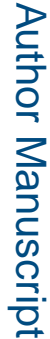

From The Way Home (Terry, 2011)

Sociol Health IIln. Author manuscript; available in PMC 2018 September 01 


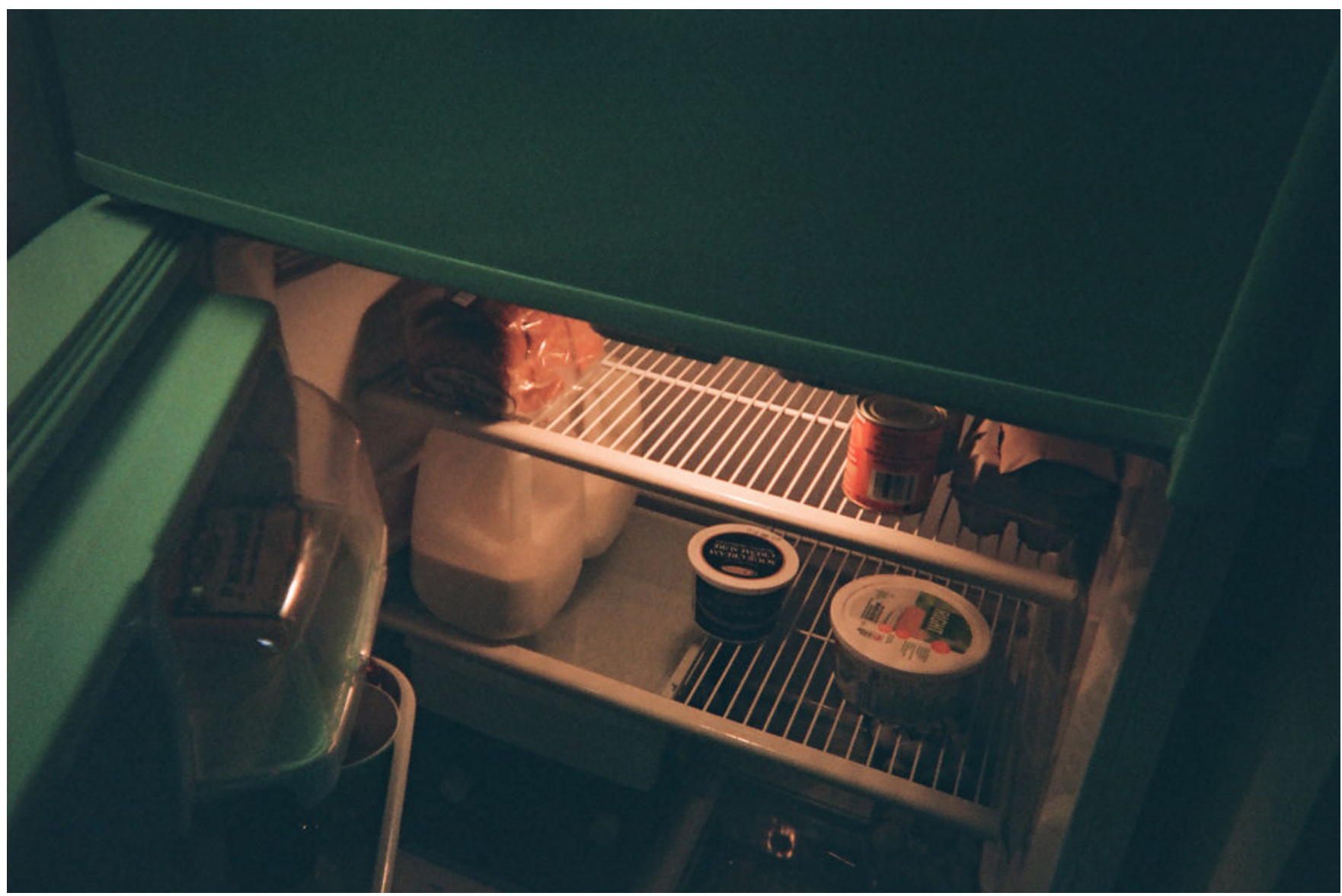

Image 3.

From Everything We Need (Carly and Conner, 2013)

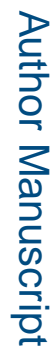




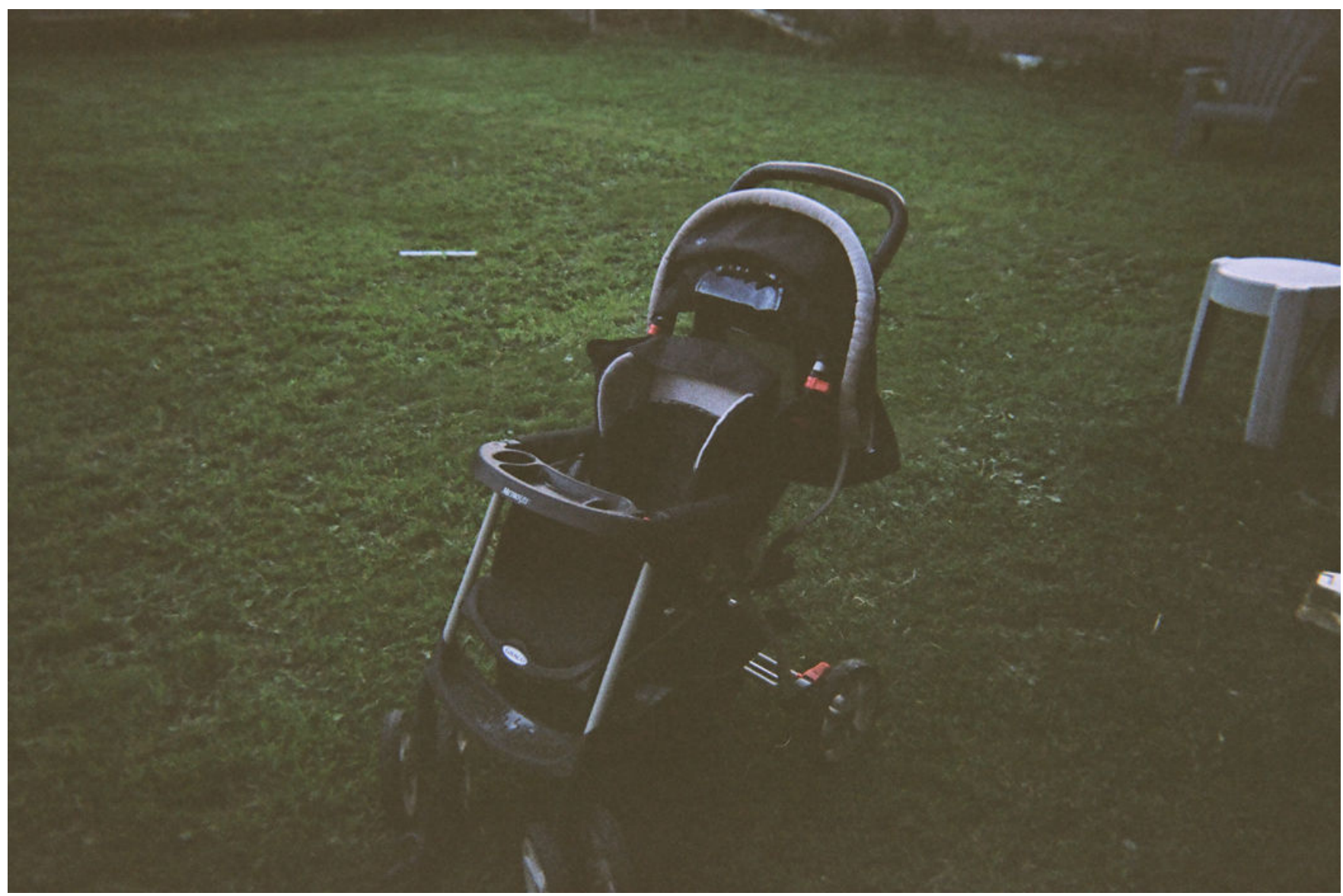

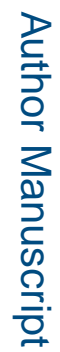

Image 4.

From Everything We Need (Carly and Connor, 2013)

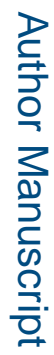




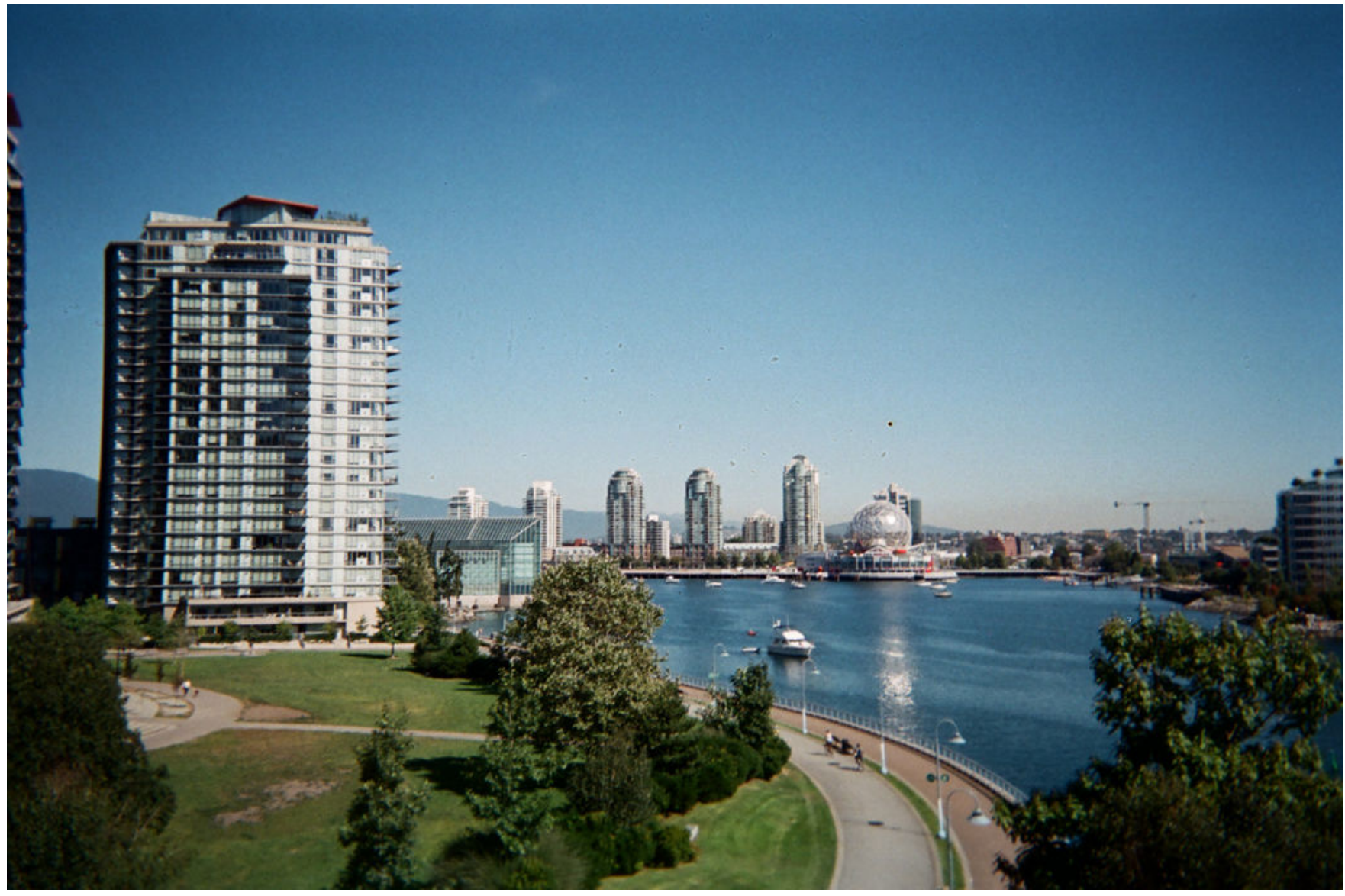

Image 5.

From Where I'm Going (Lee, 2011) 


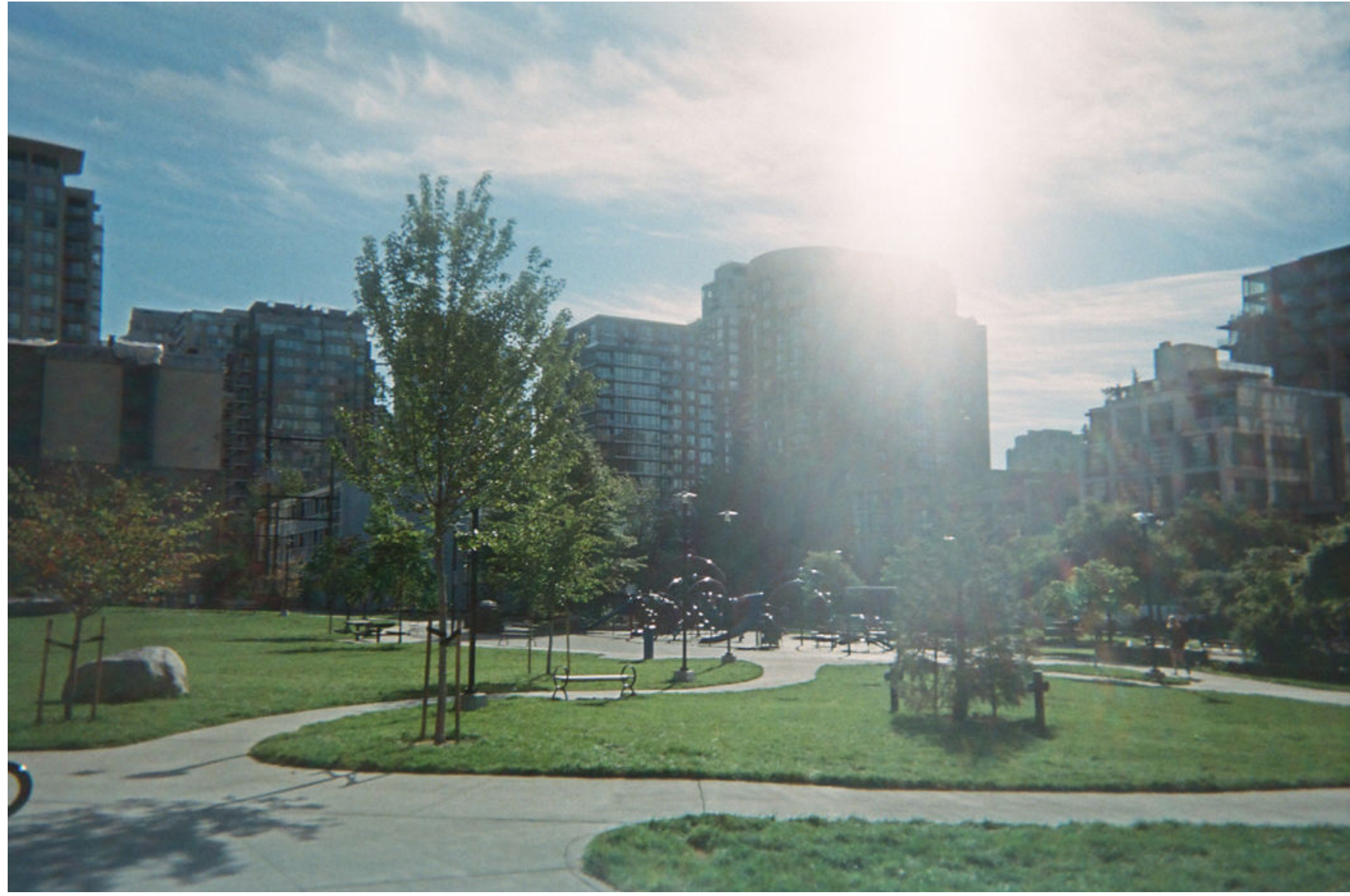

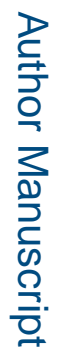

Image 6.

From Where I'm Going (Lee, 2011)

Sociol Health Illn. Author manuscript; available in PMC 2018 September 01. 


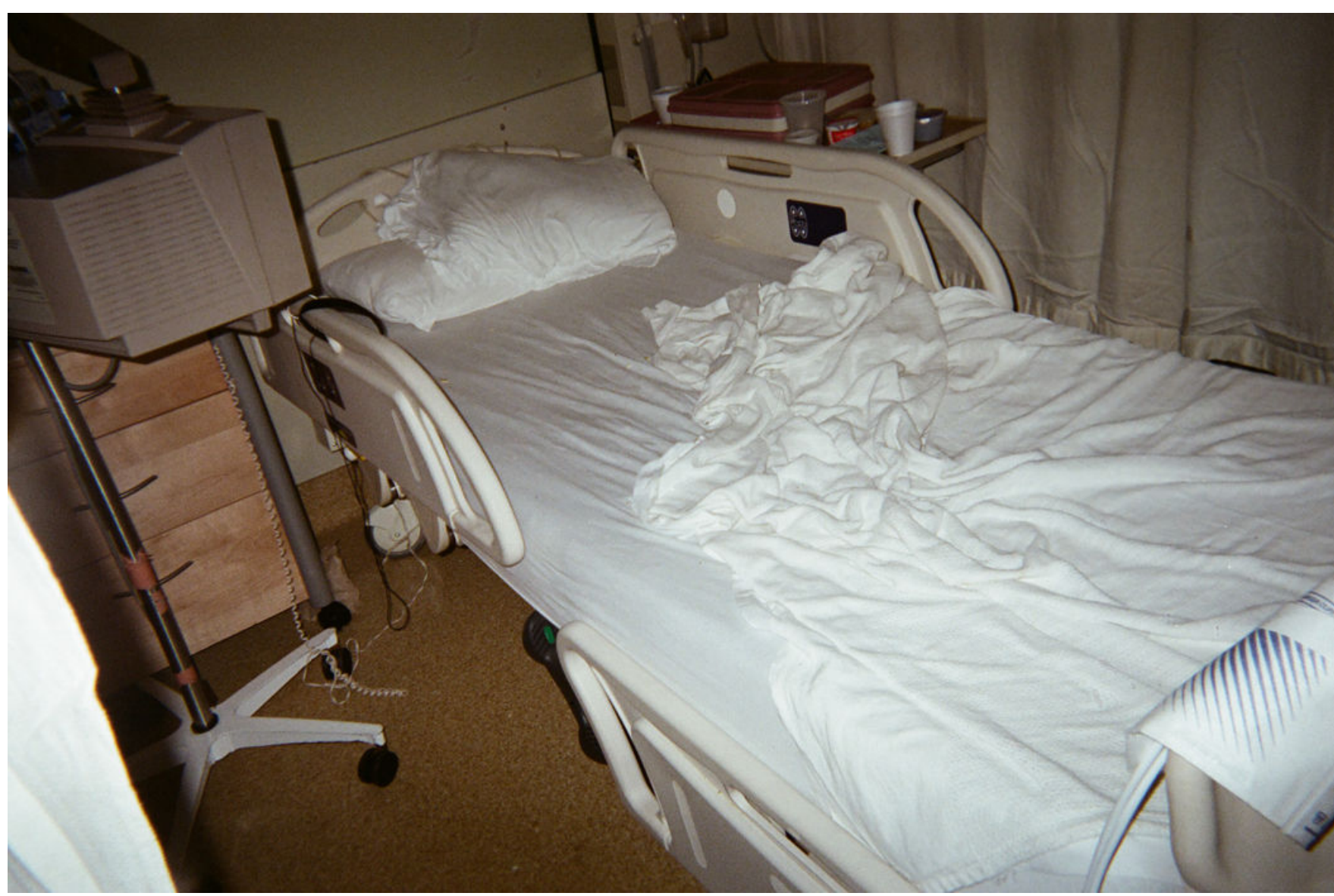

Image 7.

From Where We've Ended Up (Patty with Joe, 2014) 